\title{
Potential source regions and processes of aerosol in the summer Arctic
}

\author{
J. Heintzenberg ${ }^{1}$, C. Leck $^{2}$, and P. Tunved ${ }^{3}$ \\ ${ }^{1}$ Leibniz Institute for Tropospheric Research, Permoser Str. 15, 04318 Leipzig, Germany \\ ${ }^{2}$ Department of Meteorology, Arrhenius Laboratory, Stockholm University, 10691 Stockholm, Sweden \\ ${ }^{3}$ Department of Applied Environmental Science, Stockholm University, 10691 Stockholm, Sweden
}

Correspondence to: J. Heintzenberg (jost@ tropos.de)

Received: 22 January 2015 - Published in Atmos. Chem. Phys. Discuss.: 20 March 2015

Revised: 18 May 2015 - Accepted: 22 May 2015 - Published: 15 June 2015

\begin{abstract}
Sub-micrometer particle size distributions measured during four summer cruises of the Swedish icebreaker Oden 1991, 1996, 2001, and 2008 were combined with dimethyl sulfide gas data, back trajectories, and daily maps of pack ice cover in order to investigate source areas and aerosol formation processes of the boundary layer aerosol in the central Arctic. With a clustering algorithm, potential aerosol source areas were explored. Clustering of particle size distributions together with back trajectories delineated five potential source regions and three different aerosol types that covered most of the Arctic Basin: marine, newly formed and aged particles over the pack ice. Most of the pack ice area with $<15 \%$ of open water under the trajectories exhibited the aged aerosol type with only one major mode around $40 \mathrm{~nm}$. For newly formed particles to occur, two conditions had to be fulfilled over the pack ice: the air had spent 10 days while traveling over ever more contiguous ice and had traveled over less than $30 \%$ open water during the last 5 days. Additionally, the air had experienced more open water (at least twice as much as in the cases of aged aerosol) during the last 4 days before arrival in heavy ice conditions at Oden. Thus we hypothesize that these two conditions were essential factors for the formation of ultrafine particles over the central Arctic pack ice. In a comparison the Oden data with summer size distribution data from Alert, Nunavut, and Mt. Zeppelin, Spitsbergen, we confirmed the Oden findings with respect to particle sources over the central Arctic. Future more frequent broken-ice or open water patches in summer will spur biological activity in surface water promoting the formation of biological particles. Thereby low clouds and fogs and sub-
\end{abstract}

sequently the surface energy balance and ice melt may be affected.

\section{Introduction}

The investigation of the summer aerosol over the central Arctic Ocean began with the first Swedish Arctic icebreaker expedition (Ymer-80) in 1980 (Lannefors et al., 1983) followed up later by a series of four international icebreaker expeditions to the summer central Arctic Ocean on the Swedish icebreaker Oden in the years 1991 (Leck et al., 1996), 1996 (Leck et al., 2001), 2001 (Leck et al., 2004), and 2008 (Tjernström et al., 2014).

As illustrated in Fig. 1, several hypothesized sources may contribute to the aerosol over the central Arctic Ocean, and thus to the formation of low-level stratiform clouds and their effects on the surface energy balance. Long-range transported biomass burning or pollution plumes has been observed in helicopter profiles. These plumes always occurred in the free troposphere well above the top of the boundary layer and were rarely mixed down to the surface (Kupiszewski et al., 2013). This finding is consistent with light-absorbing surface aerosol measurements over the summer pack ice indicating extremely low concentrations on the order of a few nanograms of black carbon per cubic meter (Heintzenberg, 1982; Maenhaut et al., 1996).

Transport of precursor gases and marine biogenic particles (specifically polymer gels ${ }^{1}$ ) from the marginal ice

\footnotetext{
${ }^{1}$ Marine gels or polymer gels are produced by phytoplankton and biological secretions of sea ice algae at the sea-air interface.
} 


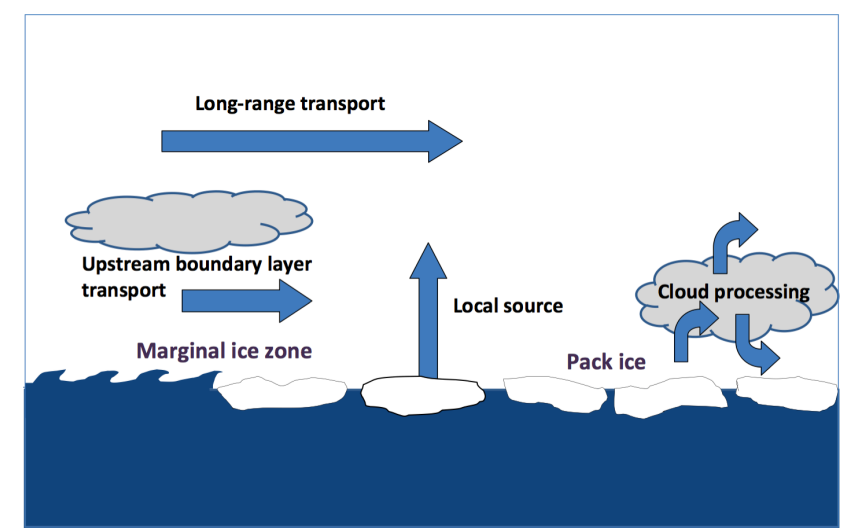

Figure 1. Schematic view of the sources and transport mechanisms of aerosol particles over the summer Arctic pack ice, adapted from Kupiszewski et al. (2013).

zone (MIZ) or locally from open leads ${ }^{2}$ over the pack ice has been found to result in raised concentrations of accumulation-mode particles within the high Arctic boundary layer (Heintzenberg et al., 2006; Chang et al., 2011; Heintzenberg and Leck, 2012; Kupiszewski et al., 2013; Hellén et al., 2012; Nilsson and Leck, 2002; Leck et al., 2013). This may involve both direct emissions of primary larger accumulation-mode marine particles, as well as growth of smaller particles via two processes, namely heterogeneous condensation and aerosol cloud processing.

Particles advected into the central Arctic within the boundary layer frequently experience efficient scavenging processes associated with low clouds and fog near the MIZ (Nilsson and Leck, 2002; Heintzenberg and Leck, 2012) which explains their later very low near-surface aerosol concentrations.

Heterogeneous condensation and aerosol cloud processing occurs when the oxidation products of dimethyl sulfide (DMS) released by phytoplankton advected from open waters south of and along the marginal ice edge (Leck and Persson, 1996a) condense on non-activated particles which then are incorporated into cloud droplets. In these droplets, liquidphase oxidation of absorbed gases can add further material to the droplet constituents. Evaporated cloud droplets leave behind raised concentrations of accumulation-mode particles, grown via the two processes described. This process creates

The polymer gels are made up of water-insoluble, heat-resistant, highly surface-active and highly hydrated (99\% water) polysaccharide molecules spontaneously forming three-dimensional networks inter-bridged with divalent ions $\left(\mathrm{Ca}^{2+} / \mathrm{Mg}^{2+}\right)$, to which other organic compounds, such as proteins and lipids, are readily bound (Gao et al., 2011; Leck et al., 2013; Orellana et al., 2011; Bigg et al., 2004).

${ }^{2}$ The high Arctic open leads can be described as ever-changing open water channels comprising $10-30 \%$ of the ice pack ice area, ranging from a few meters up to a few kilometers in width. the bimodal particle size distribution characteristic of cloudprocessed air (Hoppel et al., 1994).

New particle formation (nucleation) occurred during about $15 \%$ of the observed time period (Karl et al., 2013). However, these events often manifested themselves as a simultaneous increase of particle number concentrations in the $<10 \mathrm{~nm}$ and $20-50 \mathrm{~nm}$ size ranges, and not as the prototypical "banana growth" (see Kulmala et al., 2001). Conventional nucleation paradigms (Karl et al., 2012) fail to explain this phenomenon. An alternate hypothesis explaining this is fragmentation and/or dispersion of primary marine polymer gels, 200-500 nm diameter in size, into the nanogel size fractions down to a few nanometer polymers (Karl et al., 2013; Leck and Bigg, 2010).

While the four expeditions provided a wealth of new observations and understanding of the system of low-level clouds, their formation, and their effects on the boundarylayer and surface energy balance over the Arctic pack ice area, the ultimate partitioning of aerosol particles among potential source regions and processes remains elusive. The present paper continues the analysis of the aerosol data from the four Oden cruises with a focus on the aforementioned potential source regions and related aerosol formation processes. The ship positions during the cruises shown in Fig. 2 indicate that the measured data only cover a small part of the European Arctic sector. However, with back trajectories, the data coverage can be extended over the whole Arctic Basin. This approach was first followed with aerosol data measuring during the Ymer-80 expedition by Jaenicke and Schütz (1982) and with Norwegian Arctic aerosol data by Heintzenberg and Larsen (1983). For the present study, back trajectory information was complemented by daily maps of ice concentrations. Sections 2.3 and 2.4 provide more details. For the combination of aerosol data and information of air origin and ice data a dedicated cluster algorithm was developed. For a test of the clustering algorithm the aerosol database was complemented with the data on atmospheric DMS(g) concentrations taken during all four cruises (Leck and Persson, 1996b; Kettle et al., 1999).

To date, 23 years after the first Oden expedition, there are still no other surface aerosol data from the central Arctic to compare. The nearest land stations are Mt. Zeppelin, Spitsbergen, and Alert, Nunavut. The present paper therefore also makes an attempt to connect the size distributions taken on Oden and the clusters derived with them with size-resolved aerosol number data and trajectories from these two land stations.

With the combined data set and the clustering algorithm the main goal of the present study is to identify potential source regions of aerosol particles observed over the central summer Arctic. Specifically, we would like to differentiate between local sources within the pack ice region and distant sources. Extending our previous analyses discussed above with the locally measured parameters to different source re- 


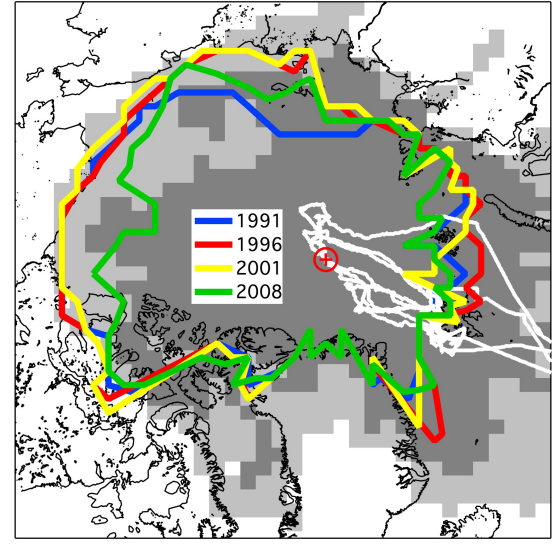

Figure 2. Map of the working area of the present study: white shows cruise tracks during the four Oden expeditions in 1991, 1996, 2001, and 2008. Red symbol: North Pole. Dark grey geocells: area covered with at least 100 trajectory hits per geocell by 5-day back trajectories in all four cruises. Additional geocells in light grey are covered likewise by 10-day back trajectories. Colored lines: $10 \%$ limit of sea ice cover north of $76^{\circ} \mathrm{N}$ estimated from average sea concentrations (https://nsidc.org/data) during each of the four Oden cruises.

gions, we aim at identifying factors controlling the aerosol life cycle over the inner Arctic.

\section{Experimental data}

\subsection{Sampling conditions on icebreaker Oden}

All four icebreaker expeditions utilized an identical sampling manifold upstream of all gas-phase and aerosol instrumentation. This manifold extended at an angle of $45^{\circ}$ to about $3 \mathrm{~m}$ above the container roof of the laboratory container on Odens' 4th deck to optimize the distance both from the sea and from the ship's superstructure. The height of the sampling manifold was $\sim 25 \mathrm{~m}$ above sea level and consisted of two masts $\left(\mathrm{PM}_{1}\right.$ : diameter $<1 \mu \mathrm{m}$ and $\mathrm{PM}_{10}$ : diameter $<10 \mu \mathrm{m}$ ), with one additional sampling line for volatile organic compounds including DMS. Direct contamination from the ship was minimized with a pollution controller. Provided that the wind was within $\pm 70^{\circ}$ of the direction of the bow and stronger than $2 \mathrm{~ms}^{-1}$, no pollution reached the sample inlets. Further details of the instrumentation and precautions to exclude contaminated periods can be found in Leck et al. (2001) and in Tjernström et al. (2014).

\subsection{Data collected onboard Oden}

\subsubsection{Gas data}

As compared to the 1271 hourly DMS values, which were concurrent with contamination-free aerosol data, a total of
$2035 \mathrm{~h}$ of DMS data were available in the four cruises for clustering.

During the expedition in 1991, integrated samples of DMS were analyzed by a gas chromatograph flame photometric detection (GC-FPD) system where a glass-fiber-wool coldtrap was used in the pre-concentration step. The sampling duration was 20 min (Persson and Leck, 1994). During the three subsequent cruises, DMS was automatically collected with a time resolution of $15 \mathrm{~min}$ and pre-concentrated in the following two steps: first, a gold trap (gold wire in a Pyrex glass tube) for collection, and second, a TENAX ${ }^{\circledR}$ medium to achieve a sharp injection of the analyte into the GC-FPD. To remove atmospheric oxidants prior to collection, a highcapacity scrubber based on $100 \%$ cotton wadding was used (Persson and Leck, 1994) in all four cruises. The overall accuracy, valid for both GC-FPD methods described above, was within $\pm 12 \%$ with a detection limit of $0.045 \mathrm{nmol} \mathrm{m}^{-3}$.

To further improve on time resolution, we added a proton transfer reaction mass spectrometer system (PTR-MS) (Lindinger and Hansel, 1998) during the 2001 cruise with a sampling frequency of $2 \mathrm{~min}$ and in the 2008 experiment DMS was measured a PTR-TOFMS (aerosol time of flight mass spectrometer) built at Innsbruck University. The PTRTOFMS was calibrated by applying a dynamically diluted DMS gas standard (Apel \& Riemer Environmental Inc.). Zero-calibrations were performed every $2-6 \mathrm{~h}$ using catalytically scrubbed air. The sampling frequency of the PTRTOFMS system was $1 \mathrm{~min}$. The instrument is described in detail in Graus et al. (2010). For the benefit of time resolution of the PTR systems, the detection limit was increased by a factor of 10 to $0.45 \mathrm{nmol} \mathrm{m}^{-3} .1 \mathrm{nmol} \mathrm{m}^{-3}=22.4 \mathrm{ppt}(\mathrm{v})$ at $0{ }^{\circ} \mathrm{C}$ and 1013.25 mbar.

\subsubsection{Aerosol data}

The Oden aerosol database is essentially the same as in Heintzenberg and Leck (2012) with $2645 \mathrm{~h}$ of submicrometer particle number size distributions between 5 and $560 \mathrm{~nm}$ diameter. Tandem differential mobility particle sizers (TDMPS) were used to measure the number size distributions of dry sub-micrometer particles with pairs of very similar differential mobility analyzers (DMAs). The TSI 3010 counters used in the DMAs were size and concentration calibrated against an electrometer and the TSI 3025 counters for particle sizes below $20 \mathrm{~nm}$ diameter in the standard way after Stolzenburg (1988). In 1996, a second, modified TSI 3010 was utilized to extend the data from 20 to $5 \mathrm{~nm}$ instead of a TSI 3025 . The harmonized size range for all cruises comprised 36 channels, which were spaced in equidistant fashion on a logarithmic scale. Before taking hourly averages, the data was cleaned thoroughly for possible pollution from the ship (see Heintzenberg and Leck, 2012, for details). In 1991, the Arctic part of the cruise covered the time from $18 \mathrm{Au}-$ gust through 26 September. In 1996, the icebreaker stayed in the pack ice region from 26 July to 4 September. The corre- 
Table 1. Start and end date and time (UTC) of the hourly Oden aerosol data utilized in the present paper in 1991, 1996, 2001, and 2008 , and the number of hourly averages after screening for possible pollution from the ship.

\begin{tabular}{lllc}
\hline Year & Start date and time & End date and time & Hours \\
\hline 1991 & 18 Aug 1991 16:00 & 26 Sep 1991 23:00 & 768 \\
1996 & 24 Jul 1996 19:00 & 4 Sep 1996 23:00 & 581 \\
2001 & 10 Jul 2001 00:00 & 25 Aug 2001 23:00 & 676 \\
2008 & 4 Aug 2008 06:00 & 7 Sep 2008 17:00 & 620 \\
\hline
\end{tabular}

sponding period in 2001 was 10 July through 25 August, and 4 August through 5 September 2008. A total of $2645 \mathrm{~h}$ of aerosol data remained after the data processing (see Table 1).

\subsection{Aerosol data from Arctic land stations}

During the most recent two cruises in 2001 and 2008 submicrometer size distribution measurements were taken at the observatory on Mt. Zeppelin $\left(78.9^{\circ} \mathrm{N}, 11.86^{\circ} \mathrm{E}\right.$; elevation 474 m a.s.1.) (Tunved et al., 2013). For comparison with the Oden data, 1968 hourly average number size distributions in 20 diameter channels from 20 to $600 \mathrm{~nm}$ were available with concurrent 5-day back trajectories.

The Dr. Neil Trivett Global Atmosphere Watch (GAW) Observatory at Alert, Nunavut $\left(82.5^{\circ} \mathrm{N}, 75^{\circ} \mathrm{W}\right.$; elevation $210 \mathrm{~m}$ a.s.l.) is the only other site close to the central Arctic with comparable aerosol measurements, i.e., regular submicrometer particle size distribution measurements starting in 2011 (Leaitch et al., 2013). Thus, no Alert size distributions are available during any Oden cruise. Instead, Alert data during the core month August of the Oden cruises will be utilized for comparison. Specifically, we have 1517 hourly average size distributions in 54 channels between 10 and $500 \mathrm{~nm}$ during August of 2011, 2012, and 2013 with concurrent 5day back trajectories arriving at $250 \mathrm{~m}$ over Alert.

\subsection{Back trajectories}

Three-dimensional back trajectories have been calculated for the three different receptor sites used in this study: the icebreaker Oden arriving at $100 \mathrm{~m}$, above sea level (a.s.l.), the observatory located on Mt. Zeppelin near Ny Ålesund, Svalbard, at $474 \mathrm{~m}$, and Alert at $250 \mathrm{~m}$. The trajectories have been calculated backward for 10 days using the HYSPLIT2 model (Draxler and Rolph, 2003) with meteorological data provided by NCEP/NCAR project for years 1991-1996 (for more information consult http://www.esrl.noaa.gov/psd/data/ gridded/data.nmc.reanalysis.html). For 2008 we applied the HYSPLIT4 model with GDAS data (Global Data Assimilation System). More information about the GDAS data set can be found from the Air Resources Laboratory (ARL), NOAA (http://ready.arl.noaa.gov/), where meteorological data also can be downloaded.
We are aware of the limitations in trajectory accuracy. On one hand the data-sparse Arctic region limits the validity of the meteorological fields on which the trajectory calculations are based. On the other hand, at the nearest continental borders the meteorological setting, surface conditions and the resulting atmospheric fields in the central Arctic are relatively simple. Figure 9 in Leck and Persson (1996b) shows an example where the trajectories were able to resolve the influence of the settlements Barentsburg and Longyearbyen on Spitsbergen in the measurements onboard Oden, which was then located near the North Pole. Assuming some $30 \%$ position uncertainty relative to the trajectory length, yielding on average $3000 \mathrm{~km}$ for a 10-day back trajectory (see Stohl, 1998), will in general not allow us to differentiate between distant regions such as the Beaufort Sea, Chukchi Sea, and Laptev Sea except for the pack ice. A distinction can be made between these seas and Kara Sea. The meteorological information calculated along the trajectories was utilized in the analysis.

Instead of discussing paths of uncertain individual trajectories, we plotted geographic results on maps of stereographic projection centered on the North Pole. These maps were covered with a coarse grid of $35 \times 39$ geocells, in which the passage of trajectories or the occurrence of other results of this study was quantified. Figure 2 shows that the geographical region covered by the back trajectories extends to and partly beyond the pack ice limits of the studied summers.

\subsection{Ice data}

Daily ice concentrations were taken from the NSIDC database (https://nsidc.org/data). The orbits of the icesensing satellites excluded the area north of about $86^{\circ} \mathrm{N}$. Here we assumed $100 \%$ ice cover. The ice data were interpolated for each hour along all back trajectories because the maps of ice concentrations for the four cruises given in Fig. 3 clearly show that not only did the extent of the sea vary considerably over the 17 years of the whole data set but also strongly within the study area. As integral parameters, the average sum of open water in percentage of each back trajectory were calculated and will be referred to as (a) OS5 (shorter than 5 days before arrival at Oden) and (b) OG5 (greater than 5 days). From the cruise-average gridded ice concentrations rough average ice limits were calculated for each cruise. For that purpose, contiguous lines of $10 \%$ ice concentrations north of $76^{\circ} \mathrm{N}$ were formed and added to Fig. 2 and to maps of individual cruise years.

\section{Clustering approach of aerosol and trajectory data}

Many clustering approaches have been developed in exploratory data analysis (Jain et al., 1999). In atmospheric aerosol research they are used to find groups of similar aerosol data, particle origin, or formation. The basic clus- 


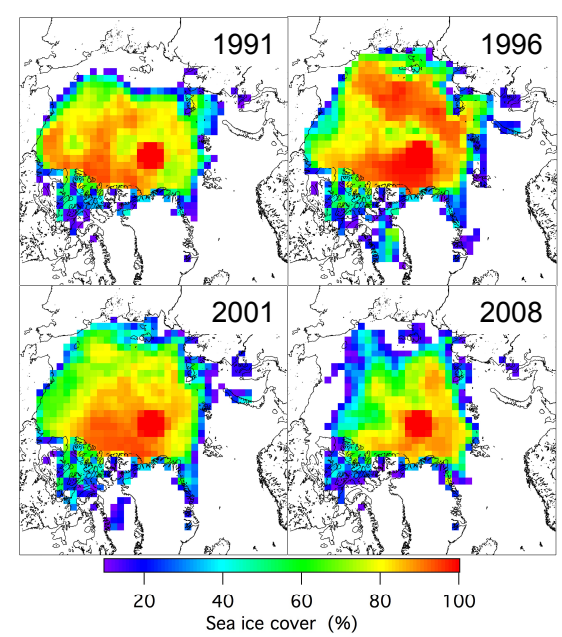

Figure 3. Gridded average Arctic sea ice cover in percent during the four Oden cruises in 1991, 1996, 2001, and 2008. Only cells with at least 100 ice pixels per cell are plotted. The blind spot of satellite data north of $86^{\circ} \mathrm{N}$ is assumed to have $100 \%$ ice cover.

tering algorithm of the present study has been introduced in Heintzenberg et al. (2013). Input aerosol data were preprocessed with the common standard normal variate (SNV) transformation by subtracting their respective grand average and dividing them by their respective standard deviations. The same SNV transformation was applied to the trajectories after projecting them onto a stereographic map centered at the North Pole. The clustering algorithm collects the clustered data in up to nine clusters based on different input information or coordinates:

$-x, y$, and/or height information of the projected trajectories,

- Percentage open water along the projected trajectories, and

- Particle number size distributions.

The algorithm can utilize any combination of these three sets of clustering coordinates, i.e., the projected horizontal coordinates of the trajectories or their combination with their height coordinates and/or open water information can be clustered, but their height coordinates alone can also be used. In each case, the resulting clusters of aerosol properties are calculated if available. Inversely, aerosol properties can be clustered, and the resulting trajectory clusters are calculated for each of such clusters. Finally, clusters can be sought based on aerosol, trajectory, and ice information.

The search algorithm is constrained by the four parameters $N_{\text {init }}, X_{\text {av }}, P$, and $C_{\text {fin }} . N_{\text {init }}$ sets the initial minimum number of members, i.e., hourly data points that any cluster is required to have before further processing. The parameter $X_{\mathrm{av}}$ is defined according to
$X_{\mathrm{av}}=\frac{\sum_{j=1, N_{i}} \sum_{k=1, m}\left(x_{j, k}-x_{j, k}\right)^{2}}{m \cdot N}$.

$m$ is the number of coordinates to be clustered. If particle size distributions are clustered, $m$ corresponds to the number of diameters. $N$ is the number of members in the respective cluster. $x_{j, k}$ is the coordinate $k$ of cluster member $j$, and $\bar{x}_{j, k}$ is the corresponding average cluster coordinate. The average distance of cluster members from a cluster average coordinate stays below a set upper limit of $X=X_{\mathrm{av}}$. The similarity of cluster members can be improved by eliminating outliers in order of their distance from the cluster average.

Initially, the algorithm allows the input data to be segregated into a maximum of nine clusters. The algorithm then eliminates the cluster with the maximum value of $\left(x_{j, k}-\bar{x}_{j, k}\right)^{2}$ for any $j$ and $k$ until the number of cluster members is reduced to $P(P \leq 1)$ times the initial number of members. Finally, the clusters are then compared to each other in order to eliminate cluster $i$ with the minimum difference $X^{\prime}$ of average coordinates from any other cluster $j$ :

$X^{\prime}=\frac{\sum_{k=1, m}\left(\bar{x}_{i, k}-\bar{x}_{j, k}\right)^{2}}{m}$,

until a given final number of clusters $C_{\text {fin }}$ is reached. The non-sequential cluster numbering in the results discussed below reflects this elimination process, i.e., any cluster number missing in the results was eliminated in this process.

Tests of the cluster algorithm with Arctic 10-day trajectories only yielded clusters with very few members. Meteorologically this finding is easily understood: after a short time very little similarity in air pathways extending over 10 days can be expected. Consequently, we limited all clustering experiments involving trajectories to 5 days. In Fig. 2, we see that the Oden cruises mainly covered the European plus western Russian sector of the inner Arctic. The trajectory coverage in Fig. 2 also shows that part of the air from the longitudinal sector opposite the Oden tracks, i.e., longitudes from about 150 to about $230^{\circ}$, took more than 5 days to reach Oden. Due to meteorological variability, transport pathways from this sector to the measuring point were less similar than in other Arctic sectors, and within 5 days the clustering algorithm could not often find many similar trajectories. Thus, in order not to miss potential source regions in this sector, a conventional longitudinal sector cluster named $\mathrm{LC}$ was added to the algorithm that combined all unclustered data, the back trajectories of which had spent at least 3 days in this sector.

Any aerosol clustering experiment lies between two extreme approaches. In the first one, as many members as possible with somewhat similar properties are combined in each cluster, in an attempt to cover the total data set as completely as possible with as few clusters as possible. Considering aerosol dynamics and the multitude of atmospheric processes, much information will be lost in this approach. The 
other extreme clustering approach is attempting to be as specific as possible, considering either air history and properties or aerosol properties in order reveal as much information as possible about potential aerosol source regions and formation processes. For the present study, the clustering was directed towards the second extreme while trying to maintain sufficient coverage and statistical relevance in order to allow general conclusions.

For the geographic spread of the trajectories of any derived cluster $i$, the metric $X_{i}$ is defined as

$X_{i}=\sum_{j=1, N_{i}} \frac{1}{n_{j}}$,

with $n_{j}$ being the number of trajectory hits in any of the $N_{i}$ geocells that are being crossed by trajectories of the respective cluster. The wider (and less regionally specific) the trajectory distribution of a cluster is, the larger $X_{i}$ becomes, and the more trajectories pass through any one cell, the narrower the spread becomes. Taken over all cruise years, the 5-day back trajectories cover a total of 554 geocells. The corresponding number for 10-day trajectories is 870 . Thus, with $X_{i}$ the fraction of possible geocells covered by the trajectories of any cluster $i$ can be visualized.

In subsequent maps, potential source regions are identified by different colors. However, each geocell can only have only one color in each map. Thus, as a measure of overlapping regions, the parameter $P_{\text {unique, } i}$ is calculated as a parameter quantifying the uniqueness of the geographic area of cluster $i$. $P_{\text {unique }}$ is the sum of the $N_{i}$ geocells that are being crossed by trajectories of cluster $i$ but of no trajectories of any other cluster; the sum is divided by $N_{i}$ and reported in percent. To increase the accuracy of this parameter, only geocells that have been passed by a minimum number of trajectories (usually 25) are being counted. Assuming independent trajectory distributions, 25 hits per geocell would correspond to a $25 \%$ uncertainty.

The quality of the particle size distributions in the derived clusters is described in two ways. With $x_{j, k}=\mathrm{d} n\left(\mathrm{~d} \log D_{p}\right) / \mathrm{d} \log \left(D_{p}\right)$ being the differential number concentration of cluster member $j$ at diameter $k$ and $\overline{\mathrm{d}} n_{j, k}$ being the arithmetic cluster average of $\mathrm{d} n_{j, k}$ the similarity of particle size distributions can be quantified for each cluster $i$. Additionally, in the graphical display of cluster-average size distributions the size-dependent standard deviations of the cluster averages are shown.

\section{Test of the trajectory clustering with DMS}

Leck and Persson (1996a, b) reported evidence for a substantial DMS source at the fringe of the central Arctic Ocean just along the MIZ, the Barents and Kara Seas being particularly strong source areas, releasing gas to the atmosphere from the uppermost ocean. This is a result of melting ice, which is favorable for the production of the DMS precursor dimethyl-

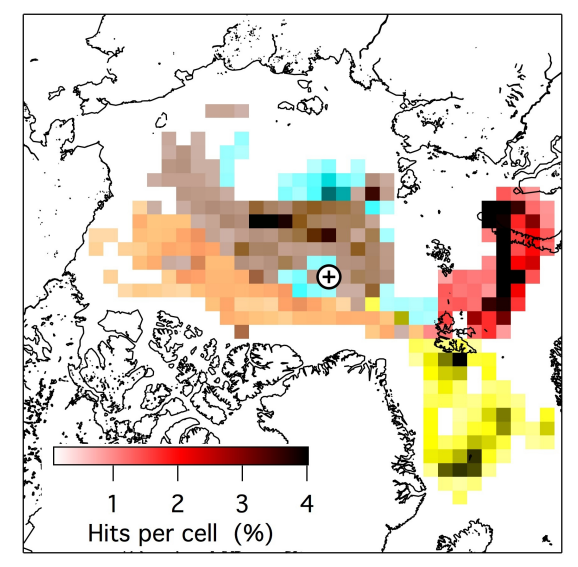

Figure 4. Regional distribution of five clusters of back trajectories with hourly DMS values of all Oden cruises. Cluster 2 is red; cluster 3 is yellow; cluster 7 is mocha; cluster 8 is Cyan; longitudinal cluster (LC) is in grey. The color saturation indicates the number of trajectory hits per geocell in percent. Only geocells with at least 25 trajectory hits are shown. The plus symbol indicates the North Pole.

sulfoniopropionate, released by the marine microbial food web. By using a three-dimensional numerical model Lundén et al. (2007) clearly showed that DMS(g) is advected with a photochemical turnover time of ca. 2.4 days (Nilsson and Leck, 2002) over the pack ice in plumes originating from the source at the ice edge or in the adjacent sea just south thereof. The above findings show that over the pack ice area, local contributions to the atmospheric DMS concentrations are negligible. At the same time DMS(g) advected from the marine source is reduced by more than an order of magnitude (Leck and Persson, 1996b).

The 5-day back trajectories (vertical dimension excluded) of all $2035 \mathrm{~h}$ in all four cruises with DMS(g) data were clustered in the DMS experiment. Run parameters of this and all other clustering experiments are listed in Table 2. Four well-separated trajectory clusters were found. An additional fifth cluster LC comprised the unclustered data in the longitudinal sector as defined in Sect. 3. On average over all years, the five clusters cover $22 \%$ of the DMS data. Key data of the five clusters are collected in Table 3 . The regional distribution of the trajectories in the clusters is plotted in Fig. 4. Clusters 2 (red) and 3 (yellow) have the highest median DMS(g) values: 11 and $2.5 \mathrm{nmol} \mathrm{m}^{-3}$, respectively. The trajectories of these two clusters clearly point towards highly source rich ice-free areas of the Greenland Sea, as well as the Barents Sea identified by Leck and Persson (1996a, b), and Lundén et al. (2007). The high average percentage of open water under the related trajectories (parameter OS5 in Table 3) corroborates these results. The remaining clusters 7 , 8 , and LC exhibited the low median DMS(g) values 0.5, 0.6, and $0.8 \mathrm{nmol} \mathrm{m}^{-3}$, respectively, together with low percentages of open water. Consequently, the test of the clustering algorithm with all available DMS(g) data has the following 
Table 2. Run parameters of the cluster experiments. Constraint stands for constraints on data input to clustering algorithm. OW means percentage of open water along the trajectories. PSD means particle size distribution. $N_{\text {init }}$ means initial number of hours required in each cluster. $X_{\mathrm{av}}$ means average distance of the cluster members from a cluster average of normalized coordinates (see Eq. 1$) . P(P \leq 1)$ means outlier reduction factor to be applied to each cluster (see Sect. 3). $C_{\text {fin }}$ means number of clusters after eliminating clusters with smallest average distance from any other cluster (see Sect. 3).

\begin{tabular}{|c|c|c|c|c|c|c|c|c|c|}
\hline Experiment & Constraint & $x$ & $y$ & OW & PSD & $N_{\text {init }}$ & $X_{\mathrm{av}}$ & $P$ & $C_{\text {fin }}$ \\
\hline DMS & None & $x$ & $x$ & & & 48 & 0.2 & 0.75 & 4 \\
\hline All aerosol & None & $x$ & $\times$ & & $x$ & 72 & 0.2 & 0.75 & 4 \\
\hline Open water & None & & & $x$ & & 24 & 0.2 & 0.9 & 8 \\
\hline Marginal ice & OG5 and OS5 $>50 \%$ & $x$ & $\times$ & & $x$ & 24 & 0.2 & 0.9 & 4 \\
\hline Pack ice low & Open water data from cluster 1 & $x$ & $\times$ & & $x$ & 48 & 0.7 & 0.5 & 3 \\
\hline Oden-Zeppelin & Concurrent time periods in 2001, 2008 & & & & $x$ & 48 & 0.05 & 0.90 & 3 \\
\hline Oden-Alert & None & & & & $x$ & 48 & 0.05 & 0.90 & 3 \\
\hline
\end{tabular}

outcome: the potential source regions identified by the algorithm in the MIZ and adjacent open waters agree with previous DMS studies. Thus, we expect the clustering algorithm to be able to identify other potential source regions of the surface aerosol over the Arctic summer pack ice.

\section{Regional distribution of potential aerosol source areas}

Encouraged by the results of the test of the clustering algorithm introduced in the previous section, we sought clusters of similar parameters in our total data set covering $2645 \mathrm{~h}$ in four Arctic summers. The combination of horizontal trajectory information and particle size distribution was segregated into five clusters covering $25 \%$ of all hourly data in the all aerosol experiment. The regional trajectory distributions of these clusters are plotted in Fig. 5 together with the average size distributions of the clusters. The trajectories of the five clusters cover different areas of the central Arctic and the open waters of the adjacent Arctic seas. All clusters except the longitudinal sector cluster LC have geographic coverage values $X_{i}$ of $\approx 20$ or less. The uniqueness parameter $P_{\text {unique, } i}$ of the five clusters are $93,66,35,44$, and $40 \%$, respectively; i.e., only $7 \%$ of the geocells of cluster 1 are hit by trajectories of other clusters, whereas $65 \%$ of the geocells of cluster 4 are passed by trajectories of other clusters as well. Low-level advection of air from the open waters of the Barents Sea $(\mathrm{OS} 5=65 \%)$ yields the typical bimodal marine size distributions (cf. Heintzenberg et al., 2004) found in cluster 1 . Its median total number of $110 \mathrm{~cm}^{-3}$ is lower than the typical $250 \mathrm{~cm}^{-3}$ found for remote marine regions in lower latitudes (Heintzenberg et al., 2004). Cluster 3, with its potential source region over the Kara Sea, has a similar bimodal shape, albeit with a much lower median total number of $37 \mathrm{~cm}^{-3}$. The small tail of the average number size distribution of cluster 3 towards the lower size limit indicates the occurrence of new particle formation in its potential source region, which is largely ice covered $(\mathrm{OS} 5=26 \%)$. Cluster 4 stems from a potential source region north of Greenland and around the North Pole with extremely low values of open water $(\mathrm{OS} 5=7 \%$, with the caveat of limited satellite coverage). In its median total number of $60 \mathrm{~cm}^{-3}$, the accumulation mode comprises but a small shoulder. The more distant cluster 5 is located in the pack-ice-covered region of the Beaufort Sea and the Canadian Archipelago (OS5 = 16\%). Whereas the average particle number size distribution associated with cluster 5 is similar in shape to that in cluster 4 , the median total number in this cluster is $80 \mathrm{~cm}^{-3}$, with somewhat higher median concentrations of particles below $10 \mathrm{~nm}$ referred to as ultrafine particles. The average particle size distribution of cluster LC differs strongly from that of the other clusters: not only is the total number about twice as high as in any of the other clusters, but these high numbers also are found at smaller diameters than in any of the other clusters, i.e., largely below $30 \mathrm{~nm}$. Median open water percentages below $30 \%$ in cluster LC clearly demonstrate that the air masses with such high concentrations of ultrafine particles have spent long periods of time over the pack ice. In general, median open water percentages in the all aerosol experiment cluster differed strongly between the clusters indicating that the amount of open water may be a controlling factor of the particle size distributions measured on Oden.

Besides the trajectories, the ice maps yield the only system parameters that cover the whole Arctic Basin. Figures 2 and 3 clearly show that both the limits and internal variability of the Arctic pack ice varied strongly during the present study. In order to explore this potentially controlling factor, we clustered the open water information along the trajectories for the total data set in the open water experiment and found two groups of clusters, each with systematic differences of open water percentages among the groups. Figure 6 a collects all trajectories of the marginal ice group, whereas Fig. 6b comprises the trajectory distribution of the pack ice group. With some overlap in the marginal ice zone reaching from Greenland to the Laptev Sea, the geographic regions of the two subpopulations are largely complementary. 
Table 3. Key data of the clusters of the cluster experiments. LC is longitudinal cluster (see Sect. 3). $X_{i}$ is the width of geographic coverage (see Eq. 4); $P_{\text {unique }}$ is the parameter of the uniqueness of geographic coverage (\%, see Sect. 3); ZAVT is the average height of trajectories during the last 5 days before arrival at Oden; OS5 is the cluster-median open water (\%) under the back trajectories during the last 5 days before arrival at Oden; $N_{\mathrm{TO}}$ is the cluster-median total particle number concentration $\left(\mathrm{cm}^{-3}\right) ; N_{10}$ is the cluster-median particle number concentration below $10 \mathrm{~nm}$ diameter $\left(\mathrm{cm}^{-3}\right) ; N_{26}$ is the cluster-median particle number concentration below $26 \mathrm{~nm} \mathrm{diameter}\left(\mathrm{cm}^{-3}\right) ; P_{24}$ is the median sum of precipitation along the last $24 \mathrm{~h}$ along the trajectories; $P_{48}$ is the median sum of precipitation along the last $48 \mathrm{~h}$ along the trajectories; $P_{5 \mathrm{D}}$ is the median sum of precipitation along the last 5 days along the trajectories; $\mathrm{n} / \mathrm{a}$ is non applicable; $\mathrm{n} / \mathrm{d}$ is no data. Aerosol and gas values for experiment Oden-Zeppelin hold for Oden data only.

\begin{tabular}{|c|c|c|c|c|c|c|c|c|c|c|c|}
\hline Experiment & Cluster & $X_{i}$ & $P_{\text {unique }}$ & OS5 & ZAVT & $N_{\mathrm{TO}}$ & $N_{10}$ & $N_{26}$ & $P_{24}$ & $P_{48}$ & $P_{5 \mathrm{D}}$ \\
\hline \multirow[t]{5}{*}{ DMS } & 2 & 4.7 & 96 & 69 & 580 & $\mathrm{n} / \mathrm{d}$ & $\mathrm{n} / \mathrm{d}$ & $\mathrm{n} / \mathrm{d}$ & $\mathrm{n} / \mathrm{d}$ & $\mathrm{n} / \mathrm{d}$ & $\mathrm{n} / \mathrm{d}$ \\
\hline & 3 & 8.4 & 87 & 91 & 260 & $\mathrm{n} / \mathrm{d}$ & $\mathrm{n} / \mathrm{d}$ & $\mathrm{n} / \mathrm{d}$ & $\mathrm{n} / \mathrm{d}$ & $\mathrm{n} / \mathrm{d}$ & $\mathrm{n} / \mathrm{d}$ \\
\hline & 6 & 14 & 65 & 50 & 50 & $\mathrm{n} / \mathrm{d}$ & $\mathrm{n} / \mathrm{d}$ & $\mathrm{n} / \mathrm{d}$ & $\mathrm{n} / \mathrm{d}$ & $\mathrm{n} / \mathrm{d}$ & $\mathrm{n} / \mathrm{d}$ \\
\hline & 7 & 12 & 27 & 20 & 260 & $\mathrm{n} / \mathrm{d}$ & $\mathrm{n} / \mathrm{d}$ & $\mathrm{n} / \mathrm{d}$ & $\mathrm{n} / \mathrm{d}$ & $\mathrm{n} / \mathrm{d}$ & $\mathrm{n} / \mathrm{d}$ \\
\hline & $\mathrm{LC}$ & 27 & 28 & 29 & 480 & $\mathrm{n} / \mathrm{d}$ & $\mathrm{n} / \mathrm{d}$ & $\mathrm{n} / \mathrm{d}$ & $\mathrm{n} / \mathrm{d}$ & $\mathrm{n} / \mathrm{d}$ & $\mathrm{n} / \mathrm{d}$ \\
\hline \multirow[t]{5}{*}{ All aerosol } & 1 & 16 & 93 & 65 & 200 & 110 & 0 & 16 & 0 & 0 & 0.1 \\
\hline & 3 & 19 & 66 & 26 & 440 & 37 & 0.5 & 6 & 0.3 & 0.4 & 2 \\
\hline & 4 & 15 & 35 & 7 & 480 & 61 & 0.3 & 8 & 0 & 0 & 3 \\
\hline & 5 & 21 & 44 & 16 & 400 & 81 & 0.1 & 30 & 0.6 & 1.2 & 5 \\
\hline & $\mathrm{LC}$ & 33 & 40 & 27 & 690 & 208 & 30 & 72 & 0 & 0 & 5 \\
\hline \multirow[t]{8}{*}{ Open water } & 1 & 21 & 23 & 10 & 380 & 100 & 0.4 & 11 & 0 & 0.1 & 4 \\
\hline & 2 & 24 & 4 & 25 & 670 & 180 & 13 & 61 & 0 & 0 & 3.9 \\
\hline & 3 & 33 & 0 & 29 & 300 & 150 & 8 & 63 & 0 & 0 & 4.3 \\
\hline & 4 & 31 & 2 & 96 & 460 & 160 & 0.6 & 13 & 0 & 0 & 3 \\
\hline & 5 & 69 & 13 & 93 & 540 & 210 & 1 & 18 & 0 & 0 & 5 \\
\hline & 6 & 20 & 6 & 25 & 390 & 130 & 60 & 64 & 0 & 0.9 & 1 \\
\hline & 7 & 21 & 18 & 88 & 110 & 170 & 0 & 23 & 1 & 1 & 1 \\
\hline & 8 & 52 & 50 & 96 & 620 & 90 & 1.9 & 22 & 0 & 0.1 & 5 \\
\hline \multirow[t]{4}{*}{ Marginal ice } & 1 & 18 & 100 & 57 & 490 & 50 & 0 & 4 & 0 & 0.2 & 12 \\
\hline & 2 & 15 & 97 & 65 & 240 & 120 & 0 & 18 & 0 & 0 & 0.3 \\
\hline & 3 & 24 & 95 & 64 & 1600 & 130 & 0 & 22 & 0 & 0 & 4 \\
\hline & 4 & 21 & 92 & 86 & 550 & 80 & 2 & 19 & 0 & 0 & 5 \\
\hline \multirow[t]{3}{*}{ Pack ice low } & 1 & 8 & 44 & 6 & 510 & 50 & 0 & 7 & 0 & 0 & 2.7 \\
\hline & 2 & 8 & 62 & 10 & 240 & 60 & 0 & 10 & 2.3 & 3.6 & 5 \\
\hline & 3 & 10 & 60 & 12 & 190 & 40 & 0 & 5 & 1.3 & 1.9 & 6.6 \\
\hline \multirow[t]{4}{*}{ Oden-Zeppelin } & 1 & 104 & $56^{\mathrm{a}}$ & $\mathrm{n} / \mathrm{a}$ & $890^{\mathrm{b}}$ & 10 & 0 & 5 & 0 & 0 & 0 \\
\hline & 2 & 38 & $0^{\mathrm{a}}$ & $\mathrm{n} / \mathrm{a}$ & $900^{\mathrm{b}}$ & 60 & 2 & 50 & 0 & 0 & 0 \\
\hline & 4 & 51 & $6^{\mathrm{a}}$ & $\mathrm{n} / \mathrm{a}$ & $740^{\mathrm{b}}$ & 50 & 0 & 13 & 0 & 0 & 0 \\
\hline & $\mathrm{LC}$ & 61 & $58^{\mathrm{a}}$ & $\mathrm{n} / \mathrm{a}$ & $1080^{\mathrm{b}}$ & 130 & 1.4 & 30 & 0 & 0 & 0 \\
\hline \multirow[t]{3}{*}{ Oden-Alert } & 1 & 190 & $162^{\mathrm{a}}$ & 23 & 710 & 30 & 0 & 7 & 0 & 0 & 0 \\
\hline & 2 & 70 & $0^{\mathrm{a}}$ & 29 & 640 & 110 & 5 & 70 & 0 & 0 & 0 \\
\hline & 3 & 170 & $41^{\mathrm{a}}$ & 25 & 910 & 90 & 0 & 10 & 0 & 0 & 0 \\
\hline
\end{tabular}

a Number of cells hit jointly by trajectories to Oden and to Mt. Zeppelin. ${ }^{\text {b }}$ At Oden, trajectories with $500 \mathrm{~m}$ arrival heights were employed.

In group one, named marginal ice, comprising clusters 4, 5,7 , and 8 (see Table 3), the median values of OG5 and OS5 were 95 and $53 \%$, respectively whereas the corresponding values of OG5 and OS5 were 27 and $25 \%$, respectively, in group two, named pack ice, comprising clusters $1,2,3$, and 6 . The clusters of the open water experiment will not be considered in detail further down. Instead a reclustering within the two groups will be discussed next.
As in the all aerosol experiment, we clustered horizontal trajectory information and particle size distributions in the marginal ice subpopulation, comprising $787 \mathrm{~h}$ after constraining the data input by requiring both OG5 and OS5 to be greater than $50 \%$. Twenty-six percent of the data was collected in the four clusters displayed in Fig. 7 in terms of their average number size distributions together with the geographic distributions of the respective cluster trajectories. Clusters 1 and 2 exhibit typical bimodal marine size distribu- 

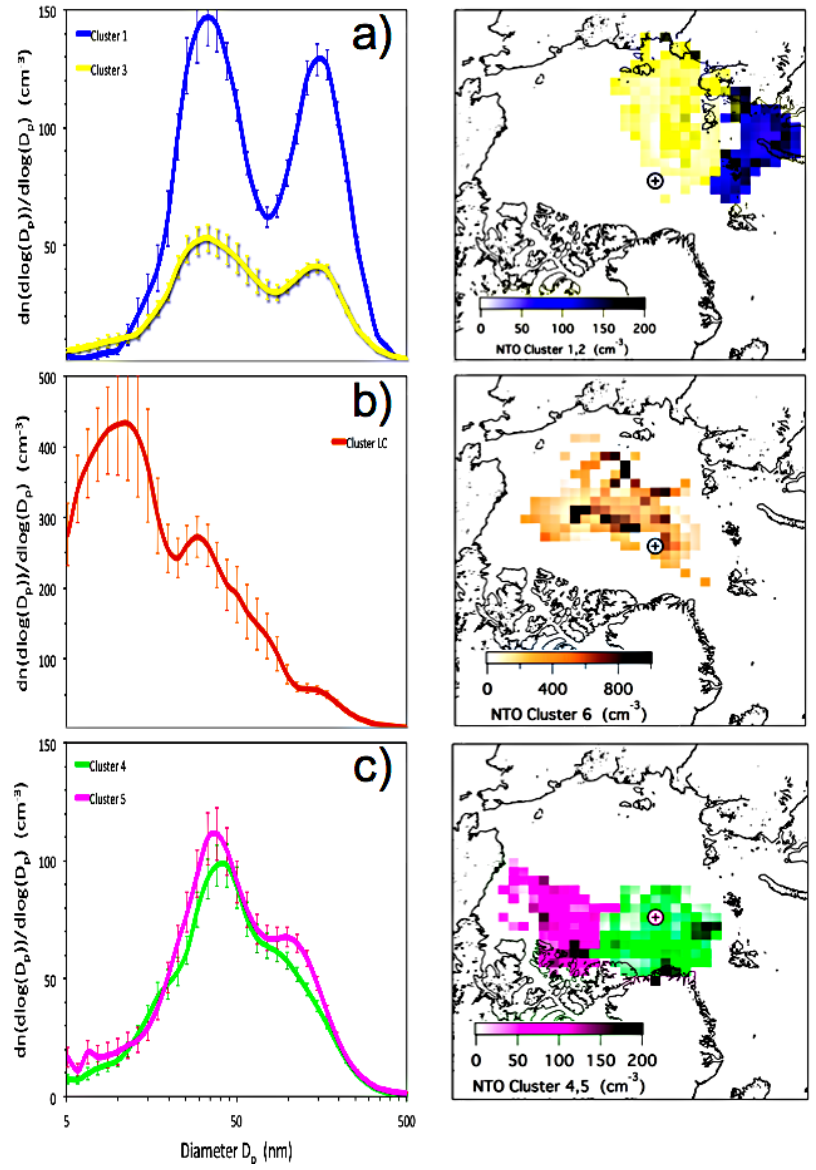

Figure 5. Left: average particle number size distributions of the five clusters of horizontal trajectory coordinates, combined with particle size distributions. The clusters are separated into (a) marine, (b) pack ice high, and (c) pack ice low. Cluster 1 is blue; cluster 3 is yellow; cluster 4 is green; cluster 5 magenta; cluster LC in copper. Error bars show 1 standard deviation about the cluster-average. Right: corresponding regional distributions of median total number concentrations (NTO, $\mathrm{cm}^{-3}$ ). The color saturation indicates the total number associated with the respective trajectory. Only geocells with at least 25 trajectory hits are shown. The plus symbol indicates the North Pole.

tions as already found in clusters 1 and 3 in all aerosol experiment (see Fig. 5), albeit with more distinct potential source regions (cf. parameter $P_{\text {unique }}$ in Table 3 ) over the open waters of the Kara and Laptev seas (cluster 1), and the North Atlantic and Barents Sea (cluster 2). The high median DMS concentration of $2.8 \mathrm{nmol} \mathrm{m}^{-3}$ in the latter cluster reflects the highly productive open waters of the respective source region.

The trajectories of cluster 3 come from the northern part of Greenland, and the average trajectory height of $1600 \mathrm{~m}$ during the last 5 days before trajectory arrival clearly point towards a free tropospheric origin of this cluster. This character is also reflected by its average number size distribution in Fig. 7c, which is essentially monomodal with its peak
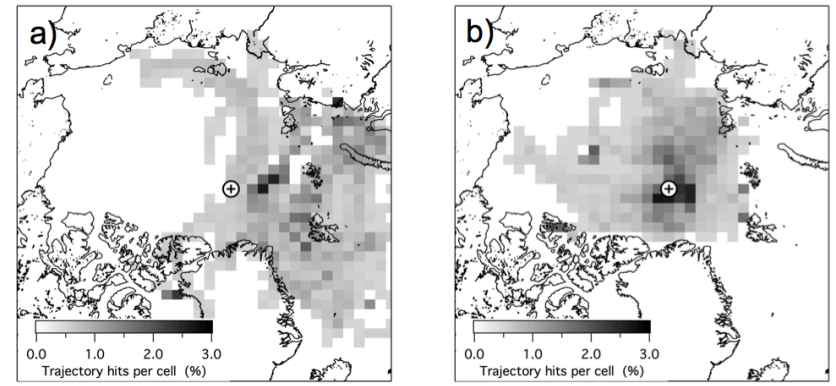

Figure 6. (a) Geographic distribution of trajectories of the marginal ice subpopulations, and (b) geographic distribution of trajectories of all data in the pack ice subpopulation.

around $40 \mathrm{~nm}$. This monomodal distribution may be the result of very long aging of polluted air in the free troposphere (e.g., Leaitch and Isaac, 1991; Parungo et al., 1990) or may indicate new particle formation with modest growth over the Greenland ice cap.

The average number size distribution of cluster 4 is shown in Fig. $7 \mathrm{~b}$ and reflects another special case of input of polluted air into the pack ice region. The small diameter of $22 \mathrm{~nm}$ of its main peak indicates a rather fresh aerosol generated in the air mass that passed over Spitsbergen. Due to the low average trajectory travel height of ca. $500 \mathrm{~m}$, the air seemingly picked up small accumulation mode characteristics around $150 \mathrm{~nm}$. A more detailed analyses of a similar case is discussed in Bigg et al. (1996) and Leck and Persson (1996b).

Next, we discuss in more detail the pack ice subpopulation (see Fig. 6b). Clustering the open water information along the trajectories yielded the four clusters 1,2,3, and 6, which according to their OS5 values clearly were associated with the inner pack ice region (see Table 3). Their cluster-average size distributions and respective geographic trajectory distributions are displayed in Fig. 8. The monomodal size distribution with low total numbers of cluster 1 in Fig. 8a resembles the aged aerosol in clusters 4 and 5 in all aerosol experiment. Cluster 1 practically covers the whole pack ice region in Fig. 6b; i.e., this type of aged aerosol may appear all over the inner Arctic. While the geographic distributions of clusters 2, 3, and 6 largely are located in the same inner pack ice region, their size distributions in Fig. $8 \mathrm{~b}$ look very different. Several peaks below $50 \mathrm{~nm}$ appear with high number concentrations (up to $900 \mathrm{~cm}^{-3}$ at sizes down to the lower diameter limit of the instruments). This type of aerosol strongly likens that of cluster LC in the all aerosol experiment (see Fig. 5).

Finally, we explored in greater detail the large geographic region of cluster 1 in the open water experiment by reclustering its $636 \mathrm{~h}$ of aerosol data with the information of horizontal trajectories and size distributions in pack ice low experiment. The results are plotted in terms of average size distributions and geographic distributions of trajectories in Fig. 9. Similar to clusters 4 and 5, all clusters of the pack ice 


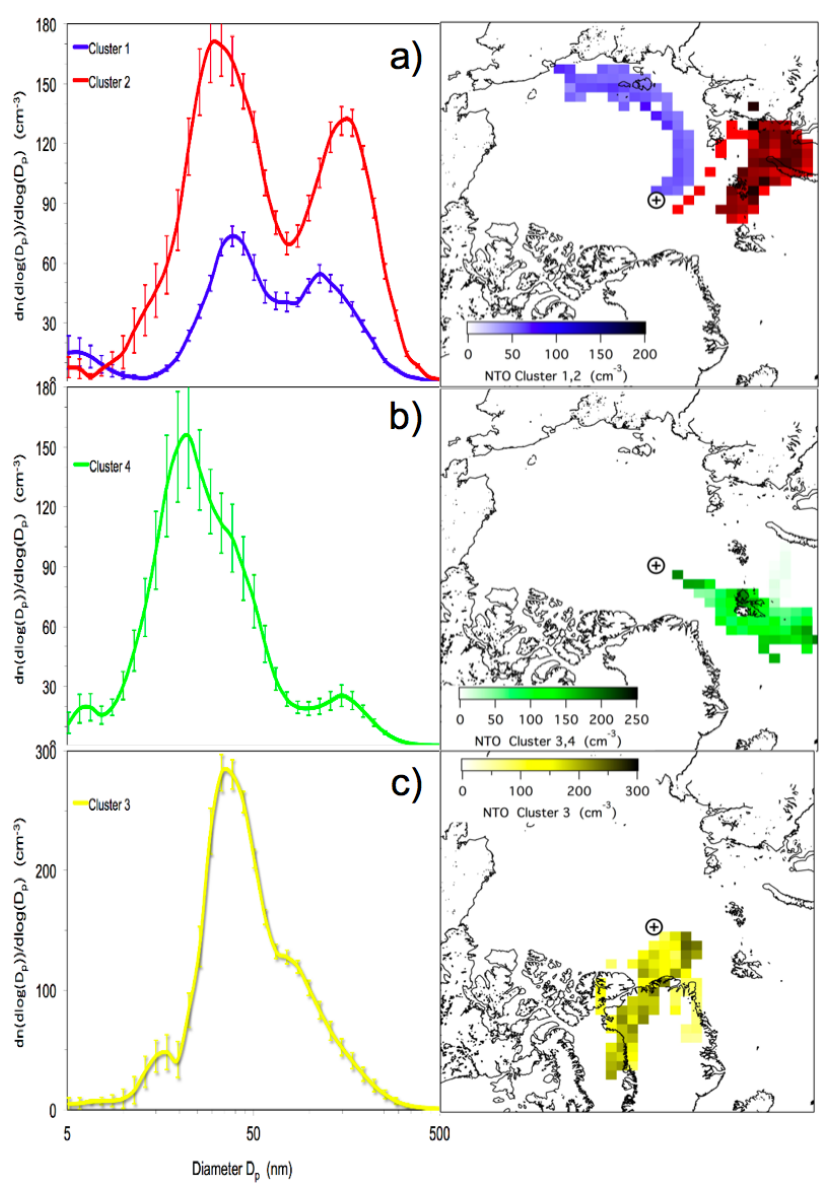

Figure 7. Left: average particle number size distributions of the four clusters of horizontal trajectory coordinates, combined with particle size distributions in the marginal ice subpopulation. The clusters are separated into (a) marine, (b) Spitsbergen, and (c) Greenland. Error bars show 1 standard deviation about the group average. Blue shows cluster 1; yellow shows cluster 3; green shows cluster 4. Right: corresponding regional distributions of median total number concentrations (NTO, $\mathrm{cm}^{-3}$ ). The color saturation indicates the total number associated with the respective trajectory. Only geocells with at least 25 trajectory hits are shown. The plus symbol indicates the North Pole.

low experiment have one main number peak around $40 \mathrm{~nm}$ and a varying second mode around $100 \mathrm{~nm}$ which may indicate some cloud processing. The similarity in size distribution while being associated with different potential source regions is due to the fact that the prescribed tight ice conditions occurred in different areas of the pack ice in different years (see Fig. 3).

\section{Comparison with the nearest land stations}

As pointed out in Sect. 1, 23 years after the first Oden expedition there are still no other surface aerosol data from the central Arctic to compare with. The nearest land stations
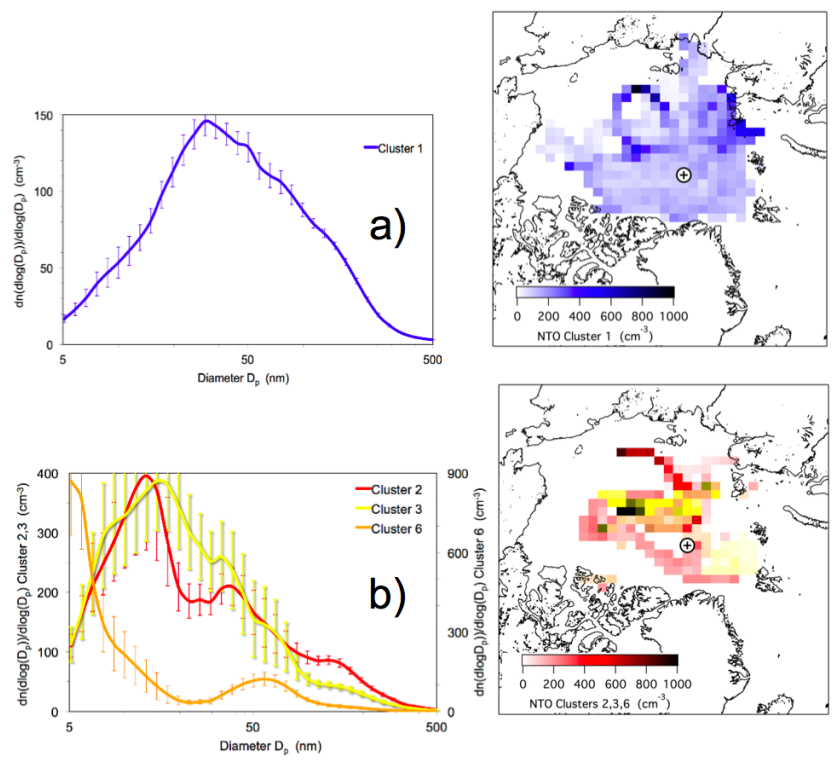

Figure 8. Left: average particle number size distributions of the four clusters of horizontal trajectory coordinates, combined with particle size distributions in the open water subpopulation. The clusters are separated into (a) pack ice low and (b) pack ice high. Error bars show 1 standard deviation about the group average. Blue shows cluster 1; yellow shows cluster 3. Right: corresponding regional distributions of median total number concentrations (NTO, $\mathrm{cm}^{-3}$ ). The color saturation indicates the total number associated with the respective trajectory. Only geocells with at least 25 trajectory hits are shown. The plus symbol indicates the North Pole.

are Mt. Zeppelin, Spitsbergen $\left(78.9^{\circ} \mathrm{N}, 11.86^{\circ} \mathrm{E}\right)$, and Alert, Nunavut $\left(82.5^{\circ} \mathrm{N}, 75^{\circ} \mathrm{W}\right)$. In this section, the size distributions taken on Oden and the clusters derived from them and back trajectories will be connected with aerosol data and trajectories from these two land stations.

\subsection{Comparison Oden/Mt. Zeppelin}

For a first comparison of particle size distributions observed at the location of the icebreaker Oden and at Mt. Zeppelin during the summers of 2001 and 2008 and the back trajectories to Mt. Zeppelin were employed. The closest points with distances less than $360 \mathrm{~km}$ between a trajectory point to the concurrent position of the icebreaker were sought along each trajectory. A total of $296 \mathrm{~h}$ fulfilled this condition with an average travel time between Oden and Mt. Zeppelin of $36 \mathrm{~h}$ and an average minimal distance between back trajectory and Oden of $177 \mathrm{~km}$. Size distributions measured on Oden at the time of minimal distance were compared to size distributions measured on Mt. Zeppelin at the time of trajectory arrival. Figure 10 shows the statistics of this comparison in terms of 25,50 , and $75 \%$ percentiles.

Absolute concentration levels and the shapes of the size distributions with their main peaks are roughly comparable 


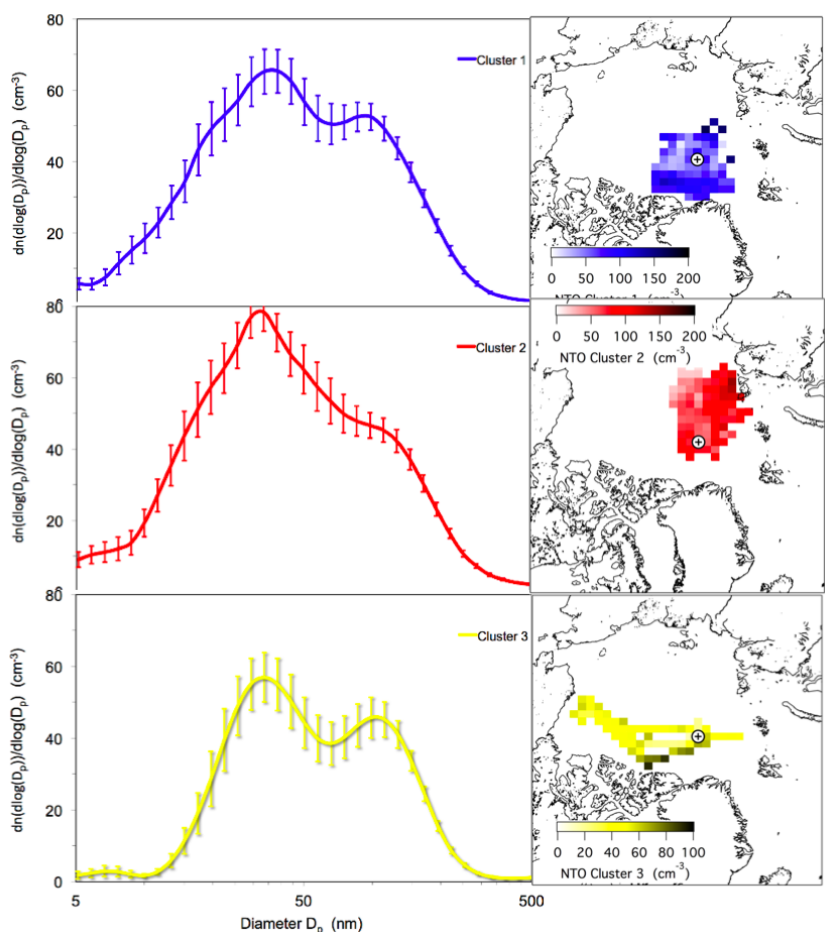

Figure 9. Left: average particle number size distributions of the four clusters of horizontal trajectory coordinates, combined with particle size distributions in the pack ice low subpopulation. Error bars show 1 standard deviation about the group average. Blue shows cluster 1; red shows cluster 2; yellow shows cluster 3. Right: corresponding regional distributions of median total number concentrations (NTO, $\mathrm{cm}^{-3}$ ). The color saturation indicates the total number associated with the respective trajectory. Only geocells with at least 25 trajectory hits are shown. The plus symbol indicates the North Pole.

at the two points, encouraging further investigation. In all three percentiles, a similar systematic change is apparent in Fig. 10. During the travel from the more central pack-icecovered Oden area to Mt. Zeppelin, concentrations decreased at all diameters larger than some $30 \mathrm{~nm}$, which could be due to cloud scavenging in the marginal ice zone.

Encouraged by this statistical comparison of trajectoryconnected data, we set up the two-station Oden-Zeppelin cluster experiment, clustering the combined particle size distribution data from the two stations. For this experiment, the size distributions on Oden and at Mt. Zeppelin had to be harmonized. The Zeppelin data of the two largest channels $(501$ and $631 \mathrm{~nm})$ were interpolated at the largest Oden diameter of $570 \mathrm{~nm}$. All Oden data were interpolated at the more coarsely spaced Mt. Zeppelin channels between 20 and $570 \mathrm{~nm}$. This harmonization yielded size distributions with 15 common diameter channels plus 11 channels from 5.1 to $20 \mathrm{~nm}$ that were only measured on Oden. These channels were set to "missing data" at Mt. Zeppelin and were not utilized in the clustering algorithm. Averages of three very dif-

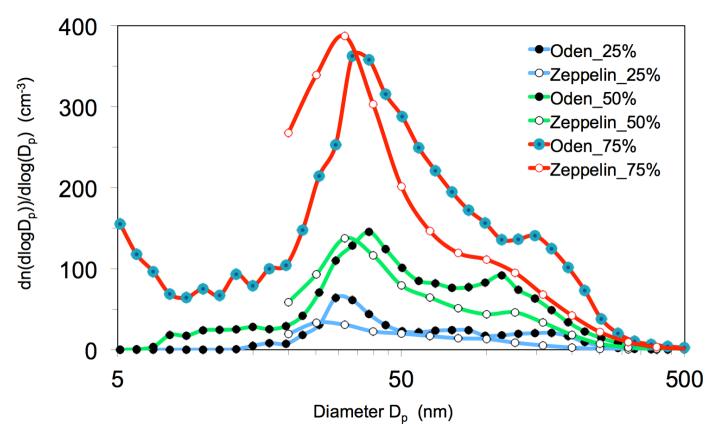

Figure 10. 25, 50, and $75 \%$ percentiles of trajectory-connected number size distributions taken during the Oden cruises in 2001 and 2008 on the icebreaker Oden and on Mt. Zeppelin, Spitsbergen.

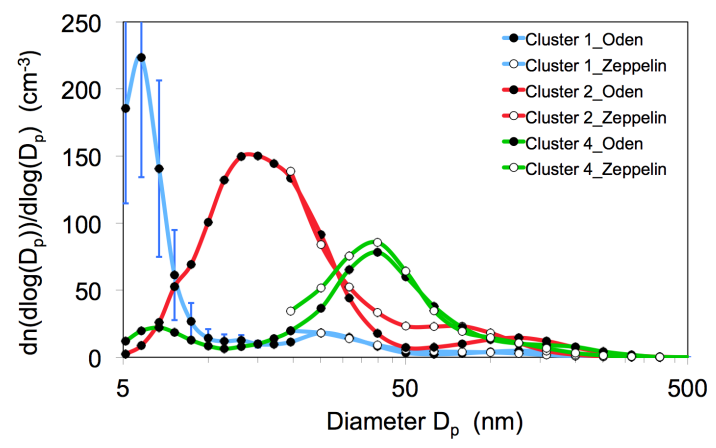

Figure 11. Average number size distributions in three clusters of harmonized size distribution data taken on Oden and on Mt. Zeppelin during the Oden cruises in the summers of 2001 and 2008. There are no Mt. Zeppelin data below $20 \mathrm{~nm}$ diameter. For cluster 1, standard deviations about the average Oden data are shown.

ferent clusters of combined size distributions are shown in Fig. 11.

Despite disregarding a direct trajectory connection in this cluster analysis, we derived quite similar cluster-average size distributions in terms of shape and absolute concentrations. Because of its lower size limit, the Mt. Zeppelin instrument could not detect freshly formed ultrafine particles. However, the steep rise towards $20 \mathrm{~nm}$ in cluster 2 of the Mt. Zeppelin data in Fig. 11 is in good agreement with the right flank of the main peak about $15 \mathrm{~nm}$ that only shows up in the Oden data.

For each cluster, the geographical distribution of 5-day back trajectories were calculated. For the Oden data in the clusters we utilized trajectories at $500 \mathrm{~m}$ arrival height in order to be more compatible with the Mt. Zeppelin trajectories arriving at $474 \mathrm{~m}$. Common potential source areas were explored by plotting the average relative occurrence of trajectory points only in geocells that were hit by back trajectories at both stations. Figure 12 presents the geographical distribution of jointly hit geocells for the three clusters in Fig. 11. The high standard deviations of the Oden data in cluster 1 below $20 \mathrm{~nm}$ indicate the rather episodic occurrence of ultrafine 


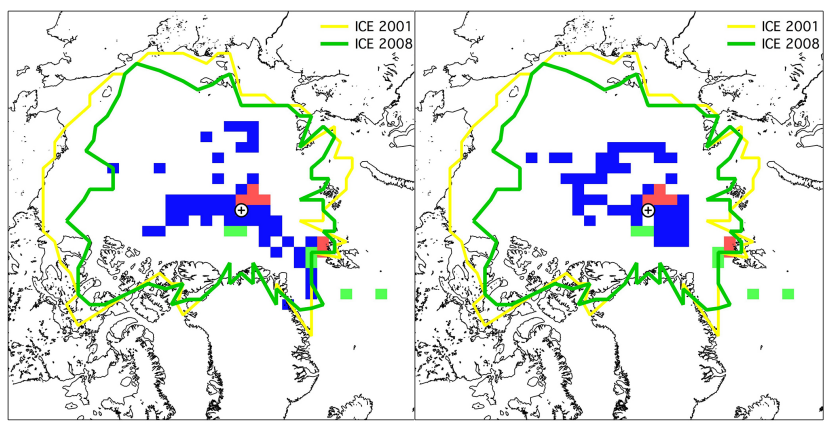

Figure 12. Geographic distribution of back trajectories for the three clusters in Fig. 11 with joint occurrences of at least 25 trajectory hits per geocell. Left: for cluster 1 only cases without particles less than $10 \mathrm{~nm}$ measured on Oden were considered. Right: for cluster 1 only cases with particle concentrations less than $10 \mathrm{~nm}>1 \mathrm{~cm}^{-3}$ measured on Oden were considered. The cluster coloring corresponds to that in Fig. 11. Colored lines: $10 \%$ limits of sea ice cover north of $76^{\circ} \mathrm{N}$ estimated from average sea concentrations (https://nsidc.org/data) during the Oden cruises of 2001 and 2008.

particles. Thus, we separated two cases of potential source areas for cluster 1 in the Oden data, one for all cases with number concentrations below $10 \mathrm{~nm}\left(N_{10}\right)=0 \mathrm{~cm}^{-3}$ measured on Oden, and one for all cases with $N_{10}>1 \mathrm{~cm}^{-3}$.

The cases of newly formed ultrafine particles were only connected with air masses from the central Arctic. Except for one geocell north of Nordaustlandet, Svalbard, cluster 2 with its main peak around $15 \mathrm{~nm}$ was also connected with air from the central Arctic. Only cluster 4 had back trajectories leading out of the pack ice limit into the North Atlantic.

\subsection{Comparison with Alert, Nunavut}

With the Oden-Alert cluster experiment commonalities were sought in the shape of the size distributions measured on Oden and at Alert. For this exercise, the data from both sites had to be harmonized in a fashion similar to the corresponding exercise with Mt. Zeppelin data. The higher resolution Alert data were interpolated at all possible diameters of the Oden data (11 to $435 \mathrm{~nm}$ ). The interpolation yielded aerosol data at 34 common diameters, which could be clustered. Disregarding the fact that they were not synchronized, we pooled the harmonized data from both sites into a set of $4877 \mathrm{~h}$ of size distributions for the clustering. With the run parameters listed in Table 2, $31 \%$ of the set were sorted into three clusters of similar shapes of size distribution. Figure 13 presents average size distributions at both sites for these three clusters. In these cluster averages, the Oden data extend the distributions to diameters between 5 and $11 \mathrm{~nm}$. Clusters 1 and 2 have bimodal shapes albeit with the Aitken-mode diameter of cluster 1 being about $10 \%$ smaller than that of cluster 2 . Cluster 3, with the highest number concentration, has only one mode in the Alert size range with its peak between 40 and $50 \mathrm{~nm}$.

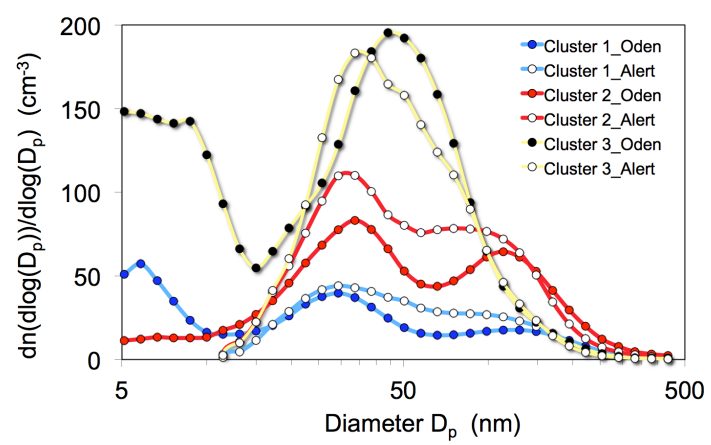

Figure 13. Average number size distributions in three clusters of harmonized particle size distributions measured on Oden during all cruises and at Alert, Nunavut during the Augusts of 2011, 2012, and 2013. There are no Alert data below $11 \mathrm{~nm}$ diameter.

The geographic distribution of back trajectories for the three clusters in the Oden-Alert experiment is collected in Fig. 14. Only geocells that are hit by back trajectories from both sites are marked. Additionally, two subpopulations of trajectories were formed. For Fig. 14 (left panel), only data without any particles less than $10 \mathrm{~nm}$ measured on Oden were utilized. No joint geocells occurred for cluster 2 in this subpopulation. The joint geocells for clusters 1 and 3 cover most of the central Arctic with branches in the open water areas of the Eurasian Arctic sectors from the Fram Strait to the Laptev Sea. In Fig. 14 (right panel), only cases with $N_{10}>1 \mathrm{~cm}^{-3}$ are collected. For cluster 1 , into which typical bimodal marine size distributions were sorted, the geographic distribution of potential source areas did not change much in Fig. 14 (right panel). Figure 14 indicates, however, that even in this type of air new particle formation was recorded on Oden. Cluster 3 with the strongest cases of new particle formation was focused onto the central Arctic when $N_{10}$ on Oden was greater than $1 \mathrm{~cm}^{-3}$. Also, joint cells of cluster 2 with its main mode around $30 \mathrm{~nm}$ appeared over the ice-covered area between Greenland and the North Pole in Fig. 14 (right panel).

\section{Synopsis and conclusions}

The present paper continues the analysis of the aerosol data from the four summer cruises of the Swedish icebreaker Oden in 1991, 1996, 2001, and 2008 with a focus on potential source regions and related aerosol formation processes as illustrated in Fig. 1. While the four cruises provided a wealth of new observations, there appears to be an inconsistency when comparing direct observations of a local particle flux from an open lead (Held et al., 2011), suggesting that the pack ice area is a net sink of aerosols, to statistical interpretations of aerosol concentrations (Heintzenberg and Leck, 2012), which suggests that the inner most Arctic is a source of sub-micrometer particles. Further support of these find- 


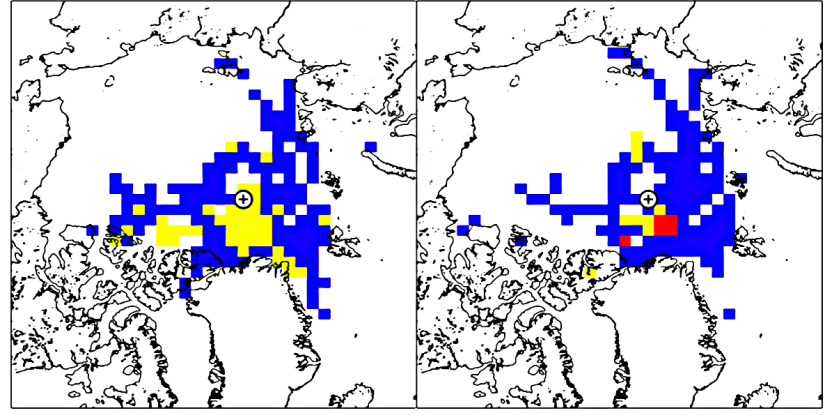

Figure 14. Geographic distribution of back trajectories for the three clusters in Fig. 13 with joint occurrences of at least 25 trajectory hits per geocell. Left: only cases without particles less than $10 \mathrm{~nm}$ measured on Oden were considered (no joint geocells for cluster 2). Right: only cases with particle concentrations less than $10 \mathrm{~nm}$ $>1 \mathrm{~cm}^{-3}$ measured on Oden were considered. The colors correspond to those in Fig. 13.

ings includes the fact that near-surface airborne aerosol, as well as low-level cloud and fog droplets, contained the same type of polymer gel material as found in the open-lead surface microlayer (Gao et al., 2012; Leck et al., 2013; Orellana et al., 2011; Bigg et al., 2004; Leck and Bigg, 2005).

When comparing the course of open water under the trajectories in this study for the two aerosol types, i.e., cluster 1, 2, 3, and 6 in the open water experiment (Fig. 8) with clusters 2, 3, and 8 of the pack ice high experiment (see Fig. 8b), significant differences between newly formed and aged aerosol over the pack ice become clear, lending further support to the findings of particle sources over the inner Arctic.

In both subpopulations the air had spent 10 days over pack ice with less than $50 \%$ open water while traveling over ever more contiguous ice. Trajectories connected with high concentrations of newly formed small particles, however, experienced more open water during the last 4 days before arrival in heavy ice conditions at Oden. Thus we hypothesize that long travel times over the more contiguous ice, combined with more open water conditions during the last few days before air mass arrival, were an essential factor controlling the simultaneous occurrence of high number concentrations at several discrete particle sizes in the $<10 \mathrm{~nm}$ and $20-50 \mathrm{~nm}$ size ranges over the Arctic pack ice. A hypothesis fitting with this chain of events could be fragmentation and/or dispersion of primary marine polymer gels, 200-500 nm diameter in size, into the nanogel size fractions down to a few nanometer polymers (Karl et al., 2013; Leck and Bigg, 2010). Fragmentation was suggested previously to be favored by evaporation of cloud or haze drops and developed by long travel times over the pack ice (e.g., Heintzenberg et al., 2006). The fragmentation hypotheses appears to be consistent with the findings of a polymer gel source at the air-sea interface (Leck et al., 2013; Orellana et al., 2011; Bigg et al., 2004; Leck

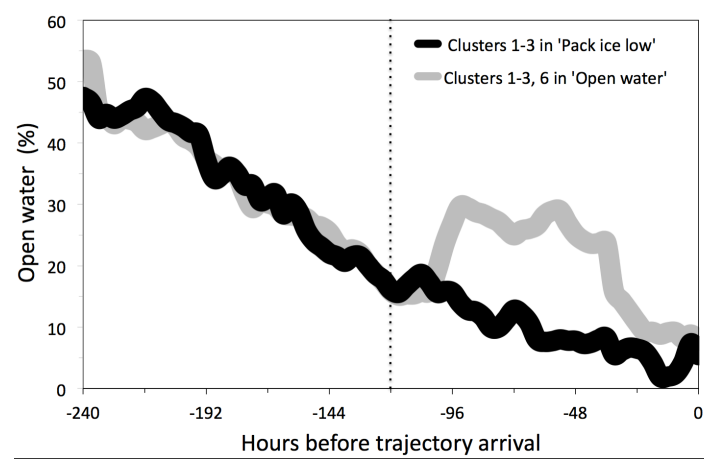

Figure 15. Median open water percentages along the trajectories of clusters 1-3 in pack ice low experiment (see Fig. 9) and those of clusters 1, 2, 3, and 6 in the open water experiment (see Fig. 8).

and Bigg, 2005; Gao et al., 2012) and may also explain why only a few percent of the observed total particle number variability at the ship was explained by the direct measurements of particle number fluxes (Held et al., 2011). Based on past and present results we conclude the inner most Arctic to be a source of sub-micrometer particles.

Even though the Alert data was taken in later years they still confirm the findings from the other sites with respect to particle sources over the central Arctic (see Figs. 13, 14). Also, our comparison with Spitsbergen data clearly identified similarities in the structure of the size distributions and, again, pointed towards particle sources in the inner Arctic (Figs. 11, 12). Conventional nucleation paradigms (Karl et al., 2012) fail to explain observations of small particle formation over the inner Arctic and those south of the pack ice. Previously reported results from Alert in summer (Leaitch et al., 2013) and on Mt. Zeppelin, Spitsbergen, in spring (Engvall et al., 2008) showed nucleation events. On Spitsbergen they were followed by prototypical banana growth (see Kulmala et al., 2001). The nucleation events at both Alert and Zeppelin are explained by a conventional nucleation mechanism involving solar radiation in concert with the presences of precursor gases and attendant low condensational sinks. A major difference between the two land stations and the inner Arctic lies in the different DMS levels. To our best knowledge (Karl et al., 2013) the extremely low DMS concentrations (Leck and Persson, 1996a, b) in the inner Arctic are not sufficient for the conventional nucleation mechanism. With this in mind, perhaps the main difference between the studies concerns how efficiently nucleation and growth of particles resulting from DMS oxidation are predicted by the choice of model and lack of observations to constrain the model assumptions.

A clear separation of marine versus pack ice aerosol was achieved by clustering the open water information along the trajectories. Then the total data set was divided into two subpopulations above and below the $50 \%$ value of average open water during the course of the trajectories. The two 
constrained data sets were investigated further for potential source regions of pack ice and marine aerosols by clustering their horizontal trajectory components. In the marine aerosol, this clustering yielded two main source regions over Laptev and Kara seas, the aerosol showing bimodal features (see Fig. 7a). Beyond that, two special cases emerged in the marine aerosol: the first case covers polluted North Atlantic air that passed over Svalbard (see Fig. 7b). The second case covers free tropospheric air that crossed Greenland before arriving at Oden (see Fig. 7c).

The subpopulations below the $50 \%$ value of average open water during the course of the trajectories indicated two different aerosol types in addition to the case of small particle formation discussed above: bimodal marine aerosol from the marginal ice zone and open seas around the pack ice (see Figs. 5a, and 9c) and an aged aerosol that also occurred frequently over the pack ice (Figs. 5c, 8a, and 9). For the former case, this may involve both direct emissions of larger polymer gel accumulation-mode particles and the growth of smaller particles via two processes, namely heterogeneous condensation and aerosol cloud processing in which the bimodal particle size distribution characteristic of cloud-processed air is created (Hoppel et al., 1994). Previous studies in the same area and season (Heintzenberg et al., 2006; Chang et al., 2011; Heintzenberg and Leck, 2012; Kupiszewski et al., 2013; Hellén et al., 2012; Nilsson and Leck, 2002; Leck et al., 2013; Leck and Persson, 1996b; Leck and Bigg, 2005) have shown raised concentrations of accumulation-mode particles within the high Arctic boundary layer which the authors attribute to sources upwind Oden: transport of precursor gases and marine biogenic particles from the MIZ or locally from open leads over the pack ice. Previously reported results of individual particles by Bigg and Leck (2001, 2008), Leck et al. (2002), and Leck and Bigg (2005a, b, 2010) collected over the pack ice however have failed to find evidence of sea salt particles of less than $200 \mathrm{~nm}$ in diameter. Larger, super-micrometer particles contained a varied and appreciable organic component shown to be polymer gels but also significant amounts of sodium chloride (Leck et al., 2002, 2013).

The frequent occurrence of the aged aerosol (Figs. 8a, and 9) was due to the subpopulation in which the air had spent 10 days over pack ice with less than $50 \%$ open water while traveling over ever more contiguous ice (see Fig. 15). This population experienced less open water during the last 4 days before arrival at Oden compared to the subpopulation of newly formed particles (see Fig. 8b). The noted relative losses of the accumulation mode can be explained by efficient scavenging processes associated with low clouds and fog near the MIZ and during the first days of advection over the pack ice (Nilsson and Leck, 2002; Heintzenberg and Leck, 2012). The loss in the sub-Aitken-mode particle sizes could have resulted from coagulation processes most efficiently when involving cloud/fog droplets (Karl et al., 2012).
What are the possible implications of our findings for the Arctic climate system? In the course of the ongoing reduction of the summer pack ice, favorable biological conditions for new particle formation might increase over the Central Arctic with more frequent broken-ice or open water patches. More open water increases biological activity in surface water, stimulating the formation of biological particles. Consequently, number concentrations of small particles might increase over the inner Arctic. Provided that enough condensates are available, e.g., DMS oxidation products or emissions from increasing Arctic shipping, more cloud condensation nuclei might result, which would affect the prevalent low clouds and fog in the summer Arctic. Changing clouds would affect the surface energy balance, which in turn would have effects on ice melt.

Acknowledgements. We are most grateful to NSIDC for providing Arctic sea ice data. In particular we are indebted to Sara, Lisa, and Terry from the NSIDC user service, who helped J. Heintzenberg with endless patience to understand the formalities of NSIDC's ice data. Richard Leaitch very kindly processed and provided the Alert aerosol data for this study.

Edited by: V.-M. Kerminen

\section{References}

Bigg, E. K. and Leck, C.: Properties of the aerosol over the central Arctic Ocean, J. Geophys. Res., 106, 32101-32109, 2001.

Bigg, E. K. and Leck, C.: The composition of fragments of bubbles bursting at the ocean surface, J. Geophys. Res., 113, D11209, doi:10.1029/2007JD009078, 2008.

Bigg, E. K., Leck, C., and Nilsson, E. D.: Sudden changes in Arctic atmospheric aerosol concentrations during summer and autumn, Tellus B, 48, 254-271, 1996.

Bigg, E. K., Leck, C., and Tranvik, L.: Particulates of the surface microlayer of open water in the central Arctic Ocean in summer, Mar. Chem., 91, 131-141, 2004.

Chang, R. Y.-W., Leck, C., Graus, M., Müller, M., Paatero, J., Burkhart, J. F., Stohl, A., Orr, L. H., Hayden, K., Li, S.-M., Hansel, A., Tjernström, M., Leaitch, W. R., and Abbatt, J. P. D.: Aerosol composition and sources in the central Arctic Ocean during ASCOS, Atmos. Chem. Phys., 11, 10619-10636, doi:10.5194/acp-11-10619-2011, 2011.

Draxler, R. and Rolph, G.: HYSPLIT (HYbrid Single-Particle Lagrangian Integrated Trajectory) Model access via NOAA ARL READY, NOAA Air Resources Laboratory, Silver Spring, MD, 2003.

Engvall, A.-C., Krejci, R., Ström, J., Treffeisen, R., Scheele, R., Hermansen, O., and Paatero, J.: Changes in aerosol properties during spring-summer period in the Arctic troposphere, Atmos. Chem. Phys., 8, 445-462, doi:10.5194/acp-8-445-2008, 2008.

Gao, Q., Matrai, P., and Leck, C.: On the chemical dynamics of extracellular polymeric secretions (polysaccharides) in the high Arctic surface microlayer, Mar. Chem., 8, 401-418, 2011. 
Gao, Q., Leck, C., Rauschenberg, C., and Matrai, P. A.: On the chemical dynamics of extracellular polysaccharides in the high Arctic surface microlayer, Ocean Sci., 8, 401-418, doi:10.5194/os-8-401-2012, 2012.

Graus, M., Müller, M., and Hansel, A.: High Resolution PTR-TOF: Quantification and Formula Confirmation of VOC in Real Time, J. Am. Soc. Mass Spectr., 21, 1037-1044, 2010.

Heintzenberg, J.: Size-segregated measurements of particulate elemental carbon and aerosol light absorption at remote Arctic locations, Atmos. Environ., 16, 2461-2469, 1982.

Heintzenberg, J. and Larsen, S.: $\mathrm{SO}_{2}$ and $\mathrm{SO}_{4}$ in the Arctic: Interpretation of observations at three Norwegian Arctic-subArctic stations, Tellus B, 35, 255-265, 1983.

Heintzenberg, J. and Leck, C.: The summer aerosol in the central Arctic 1991-2008: did it change or not?, Atmos. Chem. Phys., 12, 3969-3983, doi:10.5194/acp-12-3969-2012, 2012.

Heintzenberg, J., Birmili, W., Wiedensohler, A., Nowak, A., and Tuch, T.: Structure, variability and persistence of the submicrometer marine aerosol, Tellus, 56B, 357-367, 2004.

Heintzenberg, J., Leck, C., Birmili, W., Wehner, B., Tjernström, M., and Wiedensohler, A.: Aerosol number-size distributions during clear and fog periods in the summer high Arctic: 1991, 1996, and 2001, Tellus B, 58, 41-50, 2006.

Heintzenberg, J., Birmili, W., Seifert, P., Panov, A., Chi, X., and Andreae, M. O.: Mapping the aerosol over Eurasia from the Zotino Tall Tower (ZOTTO), Tellus B, 65, 20062, doi:10.3402/tellusb.v65i0.20062, 2013.

Held, A., Brooks, I. M., Leck, C., and Tjernström, M.: On the potential contribution of open lead particle emissions to the central Arctic aerosol concentration, Atmos. Chem. Phys., 11, 3093 3105, doi:10.5194/acp-11-3093-2011, 2011.

Hellén, H., Leck, C., Paatero, J., Virkkula, A., and Hakola, H.: Summer concentrations of NMHCs in ambient air of the Arctic and Antarctic, Boreal Environ. Res., 17, 385-397, 2012.

Hoppel, W. A., Frick, G. M., Fitzgerald, J. W., and Larson, R. E.: Marine boundary layer measurements of new particle formation and the effects nonprecipitating clouds have on aerosol size distribution, J. Geophys Res., 99, 14443-14459, 1994.

Jaenicke, R. and Schütz, L.: Arctic aerosols in surface air, Idöjaras, 86, 235-241, 1982.

Jain, A. K., Murty, M. N., and Flynn, P. J.: Data Clustering: A Review, ACM Comp. Surv., 31, 264-323, 1999.

Karl, M., Leck, C., Gross, A., and Pirjola, L.: A Study of New Particle Formation in the Marine Boundary Layer Over the Central Arctic Ocean using a Flexible Multicomponent Aerosol Dynamic Model, Tellus B, 64, 17158, doi:10.3402/tellusb.v64i0.17158, 2012

Karl, M., Leck, C., Coz, E., and Heintzenberg, J.: Marine nanogels as a source of atmospheric nanoparticles in the high Arctic, Geophys. Res. Lett., 40, 3738-3743, doi:10.1002/grl.50661, 2013.

Kettle, A. J., Andreae, M. O., Amouroux, D., Andreae, T. W., Bates, T. S., Berresheim, H., Bingemer, H., Boniforti, R., Curran, M. A. J., DiTullio, G. R., Helas, G., Jones, G. B., Keller, M. D., Kiene, R. P., Leck, C., Levasseur, M., Maspero, M., Matrai, P., McTaggart, A. R., Mihalopoulos, N., Nguyen, B. C., Novo, A., Putaud, J. P., Rapsomanikis, S., Roberts, G., Schebeske, G., Sharma, S., Simo, R., Staubes, R., Turner, S., and Uher, G.: A global database of sea surface dimethylsulfide (DMS) measurements and a simple model to predict sea surface DMS as a function of latitude, longitude and month, Global Biogeochem. Cy., 13, 399-444, 1999.

Kulmala, M., Dal Maso, M., Mäkelä, J. M., Pirjola, L., Väkevä, M., Aalto, P. P., Miikkulainen, P., Hämeri, K., and O’Dowd, C. D.: On the formation, growth and composition of nucleation mode particles, Tellus B, 53, 479-490, 2001.

Kupiszewski, P., Leck, C., Tjernström, M., Sjogren, S., Sedlar, J., Graus, M., Müller, M., Brooks, B., Swietlicki, E., Norris, S., and Hansel, A.: Vertical profiling of aerosol particles and trace gases over the central Arctic Ocean during summer, Atmos. Chem. Phys., 13, 12405-12431, doi:10.5194/acp-13-12405-2013, 2013.

Lannefors, H., Heintzenberg, J., and Hansson, H.-C.: A comprehensive study of physical and chemical parameters of the Arctic summer aerosol; results from the Swedish expedition Ymer-80, Tellus B, 35, 40-54, 1983.

Leaitch, W. R. and Isaac, G. A.: Tropospheric aerosol size distributions from 1982 to 1988 over Eastern North America, Atmos. Environ., 25A, 601-619, 1991.

Leaitch, W. R., Sharma, S., Huang, L., Toom-Sauntry, D., Chivulescu, A., Macdonald, A. M., von Salzen, K., Pierce, J. R., Bertram, A. K., Schroder, J. C., Shantz, N. C., Chang, R. Y. W., and Norman, A.-L.: Dimethyl sulfide control of the clean summertime Arctic aerosol and cloud, Elem. Sci. Anth., 1, 000017, doi:10.12952/journal.elementa.000017, 2013.

Leck, C. and Bigg, E. K.: Biogenic particles in the surface microlayer and overlaying atmosphere in the central Arctic Ocean during summer, Tellus B, 57, 305-316, 2005a.

Leck, C. and Bigg, E. K.: Source and evolution of the marine aerosol - A new perspective, Geophys. Res. Lett., 32, L19803, doi:10.1029/2005GL023651, 2005 b.

Leck, C. and Bigg, E. K.: New particle formation of marine biological origin, Aerosol Sci. Technol., 44, 570-577, 2010.

Leck, C. and Persson, C.: The central Arctic Ocean as a source of dimethyl sulfide: Seasonal variability in relation to biological activity, Tellus B, 48, 156-177, 1996a.

Leck, C. and Persson, C.: Seasonal and short-term variability in dimethyl sulfide, sulfur dioxide and biogenic sulfur and sea salt aerosol particles in the arctic marine boundary layer, during summer and autumn, Tellus B, 48, 272-299, 1996b.

Leck, C., Bigg, E. K., Covert, D. S., Heintzenberg, J., Maenhaut, W., Nilsson, E. D., and Wiedensohler, A.: Overview of the atmospheric research program during the International Arctic Ocean Expedition of 1991 (IAOE-91) and its scientific results, Tellus, 48B, 136-155, 1996.

Leck, C., Nilsson, E. D., Bigg, E. K., and Bäcklin, L.: The atmospheric program on the Arctic Ocean Expedition 1996 (AOE96): An overview of scientific goals, experimental approach, and instruments, J. Geophys. Res., 106, 32051-32067, 2001.

Leck, C., Norman, M., Bigg, E. K., and Hillamo, R.: Chemical composition and sources of the high Arctic aerosol relevant for cloud formation, J. Geophys. Res., 107, AAC1.1-AAC1.17, doi:10.1029/2001JD001463, 2002.

Leck, C., Tjernström, M., Matrai, P., Swietlicki, E., and Bigg, K.: Can marine micro-organisms influence melting of the Arctic pack ice?, EOS, 85, 25-36, 2004.

Leck, C., Gao, Q., Mashayekhy Rad, F., and Nilsson, U.: Size-resolved atmospheric particulate polysaccharides in the high summer Arctic, Atmos. Chem. Phys., 13, 12573-12588, doi:10.5194/acp-13-12573-2013, 2013. 
Lindinger, W. and Hansel, A.: Proton-transfer-reaction mass spectrometry (PTR-MS): On-line monitoring of volatile organic compounds at ppt levels, Chem. Soc. Rev., 27, 347-354, 1998.

Lundén, J., Svensson, G., and Leck, C.: Influence of meteorological processes on the spatial and temporal variability of atmospheric dimethyl sulfide in the high Arctic summer, J. Geophys. Res., 112, D13308, doi:10.1029/2006JD008183, 2007.

Maenhaut, W., Ducastel, G., Leck, C., Nilsson, E. D., and Heintzenberg, J.: Multi-elemental composition and sources of the high Arctic atmospheric aerosol during summer and autumn, Tellus B, 48, 300-321, 1996.

Nilsson, E. D. and Leck, C.: A pseudo-Lagrangian study of the sulfur budget in the remote Arctic marine boundary layer, Tellus B, 54, 213-230, 2002.

Orellana, M. V., Matrai, P. A., Leck, C., Rauschenberg, C. D., Lee, A. M., and Coz, E.: Marine microgels as a source of cloud condensation nuclei in the high Arctic, P. Natl. Acad. Sci. USA, 108, 13612-13617, 2011.

Parungo, F. P., Nagamoto, C. T., Sheridan, P. J., and Schnell, R. C.: Aerosol characteristics of Arctic haze sampled during AGASPII, Atmos. Environ., 21A, 937-949, 1990.

Persson, C. and Leck, C.: Determination of reduced sulfur compounds in the atmosphere using a cotton scrubber for oxidant removal and GC with flame photometric detection, Anal. Chem., 66, 983-987, 1994.
Stohl, A.: Computations, accuracy and applications of trajectories A review and bibliography, Atmos. Environ., 32, 947-966, 1998.

Stolzenburg, M. R.: An ultrafine aerosol size distribution measuring system, Department of Mechanical Engineering, University of Minnesota, Minneapolis, 1988.

Tjernström, M., Leck, C., Birch, C. E., Bottenheim, J. W., Brooks, B. J., Brooks, I. M., Bäcklin, L., Chang, R. Y.-W., de Leeuw, G., Di Liberto, L., de la Rosa, S., Granath, E., Graus, M., Hansel, A., Heintzenberg, J., Held, A., Hind, A., Johnston, P., Knulst, J., Martin, M., Matrai, P. A., Mauritsen, T., Müller, M., Norris, S. J., Orellana, M. V., Orsini, D. A., Paatero, J., Persson, P. O. G., Gao, Q., Rauschenberg, C., Ristovski, Z., Sedlar, J., Shupe, M. D., Sierau, B., Sirevaag, A., Sjogren, S., Stetzer, O., Swietlicki, E., Szczodrak, M., Vaattovaara, P., Wahlberg, N., Westberg, M., and Wheeler, C. R.: The Arctic Summer Cloud Ocean Study (ASCOS): overview and experimental design, Atmos. Chem. Phys., 14, 2823-2869, doi:10.5194/acp-14-2823-2014, 2014.

Tunved, P., Ström, J., and Krejci, R.: Arctic aerosol life cycle: linking aerosol size distributions observed between 2000 and 2010 with air mass transport and precipitation at Zeppelin station, Ny-Ålesund, Svalbard, Atmos. Chem. Phys., 13, 3643-3660, doi:10.5194/acp-13-3643-2013, 2013. 